\title{
Graphene oxide on the microstructure and mechanical properties of cement based composite material
}

\author{
Pang Jinchang, Wang Yeming \\ College of Architecture and Civil Engineering, Nantong Institute of Technology, Nantong, Jiangsu, 226000, China \\ pjcpangi@@163.com
}

\begin{abstract}
To investigate the mixing amount of graphene oxide and water cement ratio on the microstructure and mechanical properties of graphene oxide reinforced cement based composite material, graphene oxide suspension was developed using improved Hummers method, and the structure, size and morphology of graphene oxide were represented using Fourier transform infrared spectroscopy (FTIR), X-ray diffraction (XRD) and AFM. The results demonstrated that the bending and compressive strength of graphene oxide reinforced cement based composite material improved firstly and then declined with the increase of the mixing amount of graphene oxide, and moreover the improvement of the bending strength was obvious than that of the compressive strength. When the content of graphene oxide was $0.03 \%$, the bending strength reached the maximum, $13.73 \mathrm{MPa}$. Under a high water cement ratio, the addition of graphene oxide was more effective in enhancing the strength of cement mortar. The representation of the microstructure of cement based composite material with scanning electron microscope (SEM) suggested that graphene oxide could optimize the microstructure of cement hydration products, improve the pore structure of set cement, reduce the volume of micropore in set cement, and increase the compactness of set cement, i.e. apparently strengthen the toughening effect of set cement. The research achievements are useful to improve the mechanical properties of cement based composite materials.
\end{abstract}

KEYwORDS. Graphene oxide; Cement based composite material; Mechanical properties.

\section{OPEN ACCESS}

Citation: Jinchang, P., Yeming, W., Graphene oxide on the microstructure and mechanical properties of cement based composite material, Frattura ed Integrità Strutturale, 45 (2018) 156-163.

Received: 25.03 .2018

Accepted: 02.06 .2018

Published: 01.07.2018

Copyright: (C) 2018 This is an open access article under the terms of the CC-BY 4.0 , which permits unrestricted use, distribution, and reproduction in any medium, provided the original author and source are credited.

\section{INTRODUCTION}

$\mathrm{C}$

oncrete is the most extensively applied cement based composite material [1, 2] which is composed of cement, dinas, rebars and reinforced fibers. Concrete has been extensively applied in the construction of buildings, roads, bridges and dams for its advantages of extensive source of raw materials, low cost, simple preparation techniques and high strength [3-6]. With the development of the construction field, concrete which was a traditional structural material with high bearing capacity has developed to be more functional and environmental-friendly. Currently, high performance concrete (HPC), an important development direction of concrete, is a cement based composite material with high strength, durability 
and workability $[7,8]$. The cement composites have a noticeable feature of relatively high compressive strength and low tensile and flexural strength, which belong to brittle materials. New carbon materials such as carbon fibers and carbon nanotubes were used to enhance the strength of cement composites or provide the cement composites with improved thermal performance. Nevertheless, the reinforcing materials such as carbon fibers and carbon nanotubes only play a physical role in the cement composites and take no participation in the hydration and microstructural modification of the cement, especially the pore structure and crystalline structure of cement paste. The dispersion of carbon fibers and carbon nanotubes in the cement matrix is also challenging because of the hydrophobic surface of these reinforcing materials [9-11]. Therefore, it is urgent to find a new material which cannot only disperse uniformly in the aqueous system of hydrated cement, but also improve the toughness of hardened cement paste by microstructural modifications. Graphene oxide is an intermediate product in graphene preparation, which has many advantages as a reinforcing material such as excellent mechanical, electrical and thermal properties [12-14]. It is easy to disperse uniformly in cements, which is beneficial to the reinforcing effect. But the study on modifying traditional cement with graphene oxide is just getting started. Some scholars have investigated the modification of cement based composite material with graphene oxide. Cao et al. [9] added the modified graphene into cement and found that the addition of graphene could produce promotion and template effects on the formation of hydrate crystal product to improve the strength and tenacity of cement-based materials. Babak et al. [15] studied the mechanical properties of graphene oxide reinforced cement based composite material and found that the tensile strength had an improvement of $48 \%$ when the weight proportion of graphene oxide was $1.5 \%$. In the study of Liang et al. [16], graphite oxide was dispersed to water via ultrasound and blended with polyvinyl alcohol solution. Then polyvinyl alcohol/graphene oxide composite was prepared by volatilizing solvent via solution casting. When $0.7 \mathrm{wt} \%$ of graphene oxide was added, the tensile strength and Young's modulus of the composite was improved $76 \%$ and $62 \%$ respectively compared to pure polyving alcohol, and moreover the thermal decomposition of the composite was also improved. In this study, graphene oxide was prepared using oxidation reduction to study the effects of different mixing amount of graphene oxide and water cement ratio on the mechanical properties (bending and compressive strength) and microstructure of cement based composite material and analyze the variation rules. This work aims to figure out the influencing mechanism of the mixing amount of graphene oxide and water cement ratio on graphene oxide reinforced cement based composite material to lay a basis for the application of graphene oxide in cement based material.

\section{EXPERIMENTAL SCHEME}

\section{$\mathrm{M}$}

Experimental materials aterials included graphite powder (granularity $\leq 30 \mu \mathrm{m}$, Sinopharm Chemical Reagent Co., Ltd., China), concentrated sulfuric acid $\left(\mathrm{H}_{2} \mathrm{SO}_{4}, 98 \%\right.$ mass fraction), potassium permanganate $\left(\mathrm{KMnO}_{4}\right.$, mass fraction $\geq$ 99.5\%), concentrated phosphoric acid ( $\mathrm{HPO}_{3}$, mass fraction $\geq 85 \%$ ), hydrogen peroxide $\left(\mathrm{H}_{2} \mathrm{O}_{2}, 30 \%\right.$ mass fraction), polycarboxylate superplasticizer, ordinary portland cement P.O.42.5 and ISO standard sand.

\section{Preparation of graphene oxide}

$1 \mathrm{~g}$ of graphite powder and $46 \mathrm{~mL}$ of concentrated sulfuric acid were added into a conical flask. The temperature was kept below $3{ }^{\circ} \mathrm{C}$. Then $6 \mathrm{~g}$ of $\mathrm{KMnO}_{4}$ was slowly added during stirring for $2 \mathrm{~h}$ of reaction at $15^{\circ} \mathrm{C}$ and $10 \mathrm{~h}(20 \mathrm{~h} / 30 \mathrm{~h} / 40 \mathrm{~h})$ of reaction at $35^{\circ} \mathrm{C}$; the reactant turned to be green. Then $100 \mathrm{~mL}$ of deionized water was slowly added for 30 min of reaction at $80{ }^{\circ} \mathrm{C}$. After the addition of $15 \mathrm{~mL}$ of $30 \%$ hydrogen peroxide, the reactant turned to be golden yellow; the reaction continued for $30 \mathrm{~min}$. Next centrifugation and washing with deionized water were performed until there was no $\mathrm{SO}_{4}^{2-}$ in the washing liquid. The value of $\mathrm{pH}$ was adjusted to 7.0. It was processed by ultrasonic wave under $500 \mathrm{~W}$ for 30 min to obtain graphene oxide dispersion liquid after the addition of polycarboxylate superplasticizer. Its mass fraction was controlled at $0.2 \%$.

\section{Representation of graphene oxide}

The X-Ray Diffraction (XRD) of graphite and graphite oxide were detected using D/max 2200 PC X-ray diffractometer (Rigaku, Japn). $\mathrm{Cu} \mathrm{K} \alpha$ was X-ray source. The test was performed under $40 \mathrm{kV}$ and $40 \mathrm{~mA}$, and the angle was between $2^{\circ}$ and $70^{\circ}$.

IRPrestige-21 Fourier transform infrared spectrometer was used to represent the molecular structure and functional group of graphene oxide and identify the category of the functional group. Specimens used for Fourier Transform Infrared Spectroscopy (FTIR) was dried using a dryer and ground into powder. KBr pellet pressing method was used. 
The size of graphene oxide nanosheets was detected using SPI3800N/SPA400 atomic force microscope (NSK, Japan). 0.5 $\%$ graphene oxide was diluted to 1500 times, and one drop was taken and dried on a monocrystalline silicon piece (10 mm $\times 10 \mathrm{~mm}$ ) at $25^{\circ} \mathrm{C}$.

\section{Preparation of graphene oxide reinforced cement based composite material}

It has been found that the addition of a small amount of nanometer material can significantly improve various performances of composite materials $[17,18]$. In this study, the mass fraction of graphene oxide was set as $0 \%, 0.01 \%, 0.03 \%, 0.05 \%$ and $0.07 \%$ to study the effects of the mixing amount of graphene oxide on the mechanical properties of test specimens. Water cement ratio is an important parameter determining the strength, working performance and durability of cement based composite material [19]. Water cement ratio was set as $0.35,0.4,0.45$ and 0.5 to investigate the variation rules of the mechanical strength of specimens under the same mixing amount of graphene oxide and different water cement ratio. $0.2 \%$ polycarboxylate superplasticizer was added to all the specimens to solve the problem of reduced fluidity caused by the addition of graphene oxide [20].

According to the preparation techniques described in Method of testing cements - Determination of strength (GB176711999), cement mortar was put into a mould in a size of $40 \mathrm{~mm} \times 40 \mathrm{~mm} \times 160 \mathrm{~mm}$ for curing. Then the test specimens were developed as per the mix proportion shown in Tab. 1 for the compressive and bending strength tests. All the specimens were demoulded after $24 \mathrm{~h}$ of maintenance and then maintained in water under standard conditions, i.e. $20{ }^{\circ} \mathrm{C}$ and $90 \%$ relative humidity, before test.

\begin{tabular}{|c|c|c|c|c|c|}
\hline $\begin{array}{c}\text { No. of } \\
\text { specimen }\end{array}$ & Cement/g & $\begin{array}{l}\text { Water } \\
\text { cement ratio }\end{array}$ & $\begin{array}{c}\text { Standard } \\
\text { sand } / g\end{array}$ & $\begin{array}{l}\text { Graphene } \\
\text { oxide/wt } \%\end{array}$ & $\begin{array}{c}\text { Polycarboxylate } \\
\text { superplasticizer/wt } \\
\%\end{array}$ \\
\hline 1 & \multirow{10}{*}{450} & 0.35 & \multirow{10}{*}{1350} & 0 & \multirow{10}{*}{0.2} \\
\hline 2 & & 0.35 & & 0.01 & \\
\hline 3 & & 0.35 & & 0.03 & \\
\hline 4 & & 0.35 & & 0.05 & \\
\hline 5 & & 0.4 & & 0 & \\
\hline 6 & & 0.4 & & 0.03 & \\
\hline 7 & & 0.45 & & 0 & \\
\hline 8 & & 0.45 & & 0.03 & \\
\hline 9 & & 0.5 & & 0 & \\
\hline 10 & & 0.5 & & 0.03 & \\
\hline
\end{tabular}

Table 1: The mix proportion of cement mortar specimens.

Test on the mechanical properties of cement mortar

The test specimens were taken out from water and dried, and then the bending and compressive strength of the specimens were detected under $50 \mathrm{~N} / \mathrm{s}$ and $2400 \mathrm{~N} / \mathrm{s}$ following GB17671-1999. In each group, three test specimens were tested, and the average value was taken as the final result. Samples were collected from the crashed fracture surface of the test specimens and immersed in absolute ethyl alcohol to stop hydration, and finally preserved in a vacuum drier. Energy spectrum was analyzed using an American JSM-6360LV scanning electron microscope (SEM) and a spectrometer.

\section{TEST RESULTS AND ANALYSIS}

\section{Analysis of Representation of Graphene Oxide}

he XRD spectra of graphite powder and graphite oxide sample are shown in Fig. 1. The peak in the curve (a) of Fig. 1 was the characteristic peak of graphite, and the peak in the curve (b) was the characteristic peak of graphene oxide. The results demonstrated that the interlayer spacing of graphene oxide increased from $0.33855 \mathrm{~nm}$ to $0.83859 \mathrm{~nm}$, which contributed to the introduction of oxygen-containing groups in graphite nanosheets under oxidation. Oxygen connected with graphene in the form of a covalent bond, leading to the changes of laminated structure and diffraction peak deviation of graphene oxide. 


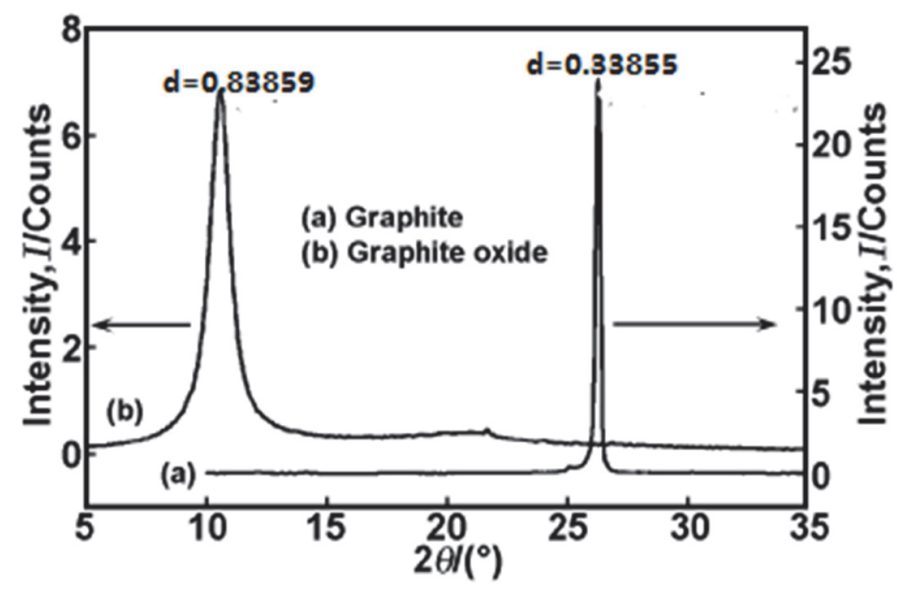

Figure 1: The XRD spectra of graphite and graphite oxide.

The FTIR spectrum of graphite oxide is shown in Fig. 2. As shown in Fig. 2, the stretching vibration and bending vibration peaks of $-\mathrm{OH}$ in water molecule were at $3394 \mathrm{~cm}^{-1}$ and $1622 \mathrm{~cm}^{-1}$ respectively, the the stretching vibration and bending vibration peaks of -OH in hydroxyl group were at $3141 \mathrm{~cm}^{-1}$ and $1401 \mathrm{~cm}^{-1}$ respectively, the stretching vibration peak of $\mathrm{C}=\mathrm{O}$ in carboxyl group and carbonyl group at the edge of graphite oxide nanosheets was at $1727 \mathrm{~cm}^{-1}$, and the stretching vibration peaks of C-O-C/-C-O were at $1116 \mathrm{~cm}^{-1}$ and $1075 \mathrm{~cm}^{-1}$. The existence of those characteristic peaks suggested that oxygen-containing groups such as carboxyl group, epoxy group and carbanyl group were introduced in the preparation of graphite oxide, i.e. graphite has been successfully oxidized.

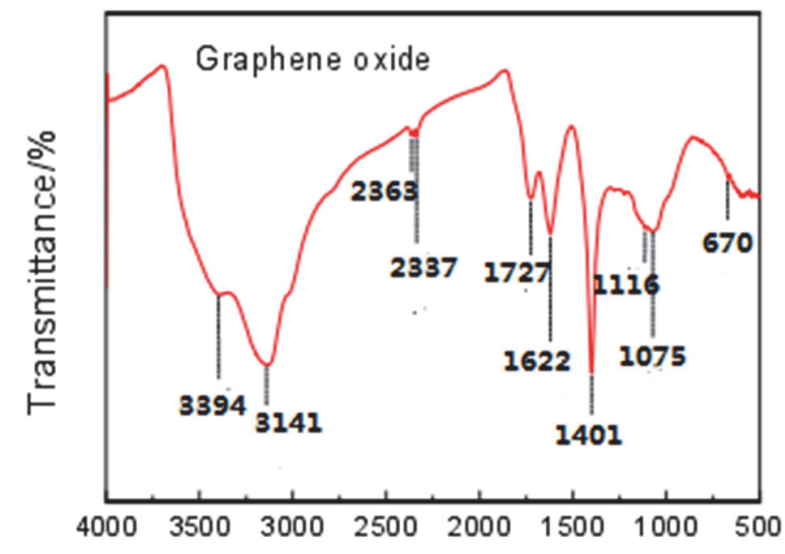

Figure 2: The FTIR spectrum of graphite oxide.

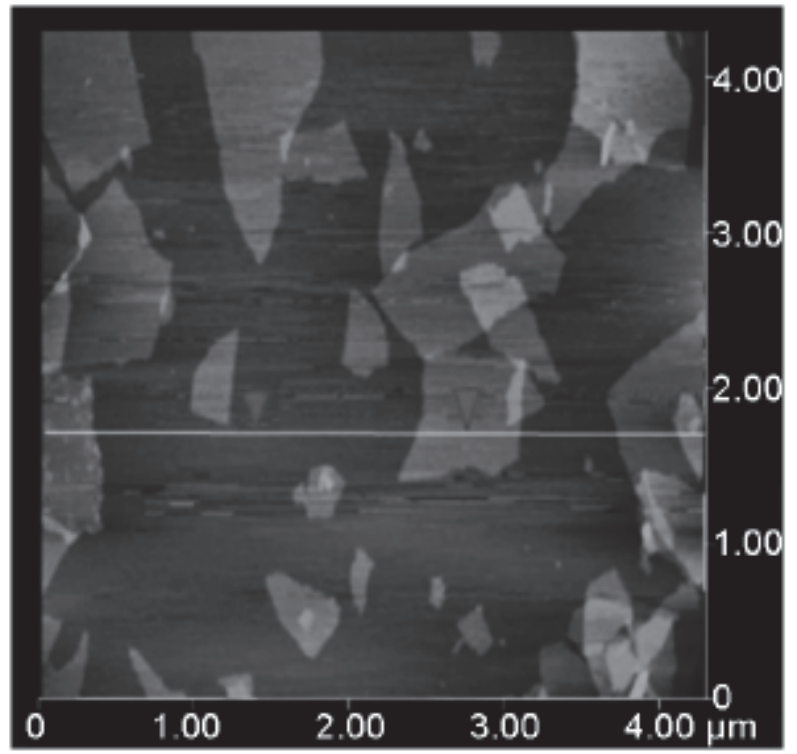

Figure 3. AFM image of graphene oxide nanosheets.

AFM image of graphite oxide is shown in Fig. 3. It can be seen from Fig. 3 that the size and thickness of graphite oxide sheet were 100-1000 and $0.7 \mathrm{~nm}$, respectively, indicating that graphite oxide is one or two atom thick layers. It suggested that the prepared graphite oxide with oxygen-containing functional group on the surface had favorable dispersion and peeling.

Effects of the Mixing Amount of Graphene Oxide on the Mechanical Properties of the Test Specimens

The bending and compressive strength of the prepared graphene oxide reinforced cement based composite material were tested, as the results are shown in Tab. 2 and 3. 


\begin{tabular}{ccccccc}
\hline $\begin{array}{c}\text { No. of } \\
\text { test } \\
\text { specimen }\end{array}$ & $\begin{array}{c}\text { Water } \\
\text { cement } \\
\text { ratio }\end{array}$ & $\begin{array}{c}\text { Mixing amount } \\
\text { of graphene } \\
\text { oxide/ }(\%)\end{array}$ & $\begin{array}{c}\text { Bending } \\
\text { strength/ } \\
\mathrm{MPa}\end{array}$ & $\begin{array}{c}\text { Growth rate } \\
\text { of bending } \\
\text { strength/(\%) }\end{array}$ & $\begin{array}{c}\text { Compressive } \\
\text { strength/MPa }\end{array}$ & $\begin{array}{c}\text { Growth rate of } \\
\text { compressive } \\
\text { strength/(\%) }\end{array}$ \\
\hline 1 & 0.35 & 0 & 11.07 & & 65.66 & \\
2 & 0.35 & 0.01 & 11.12 & 0.28 & 68.07 & 3.66 \\
3 & 0.35 & 0.03 & 13.73 & 23.82 & 72.78 & 10.86 \\
4 & 0.35 & 0.05 & 9.96 & -10.21 & 55.42 & -15.61 \\
\hline
\end{tabular}

Table 2: The basic mechanical properties of cement mortar under different mixing amount of graphene oxide.

\begin{tabular}{ccccccc}
\hline $\begin{array}{c}\text { No. of test } \\
\text { specimen }\end{array}$ & $\begin{array}{c}\text { Water } \\
\text { cement } \\
\text { ratio }\end{array}$ & $\begin{array}{c}\text { Mixing amount } \\
\text { of graphene } \\
\text { oxide/(\%) }\end{array}$ & $\begin{array}{c}\text { Bending } \\
\text { strength/ } \\
\mathrm{MPa}\end{array}$ & $\begin{array}{c}\text { Growth rate } \\
\text { of bending } \\
\text { strength/(\%) }\end{array}$ & $\begin{array}{c}\text { Compressive } \\
\text { strength/MPa }\end{array}$ & $\begin{array}{c}\text { Growth rate of } \\
\text { compressive } \\
\text { strength/(\%) }\end{array}$ \\
1 & 0.35 & 0 & 11.07 & & 65.66 & \\
3 & 0.35 & 0.03 & 11.13 & 23.82 & 72.78 & 10.86 \\
5 & 0.4 & 0 & 10.41 & & 63.84 & \\
6 & 0.4 & 0.03 & 11.85 & 10.49 & 67.95 & 6.42 \\
7 & 0.45 & 0 & 9.32 & & 60.44 & 8.60 \\
8 & 0.45 & 0.03 & 10.94 & 17.41 & 65.66 & 72.36 \\
9 & 0.5 & 0 & 5.77 & & 30.57 & \\
10 & 0.5 & 0.03 & 9.98 & 73.10 & 52.66 & 760 \\
\hline
\end{tabular}

Table 3: The basic mechanical properties of cement mortar under different water cement ratios.
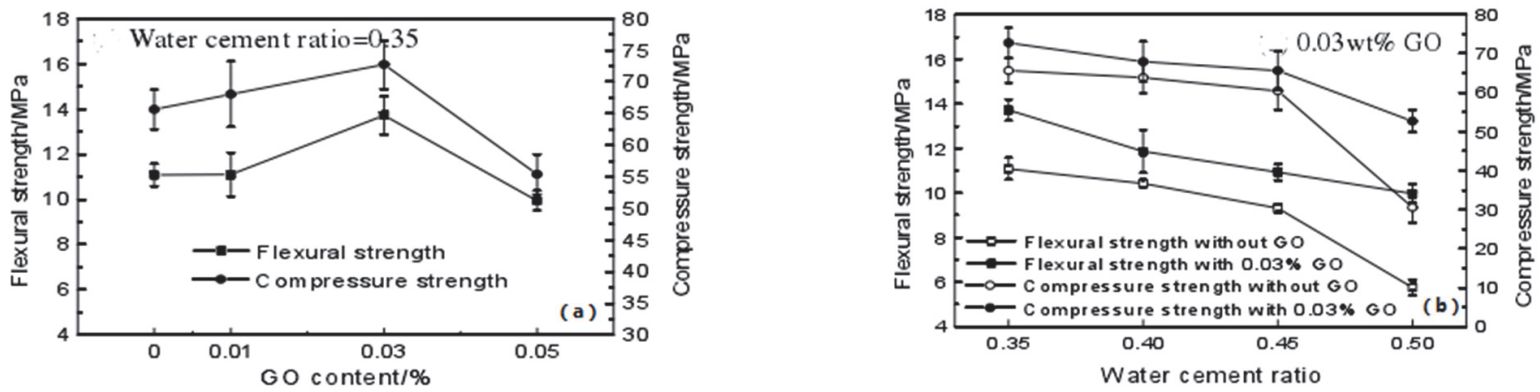

Figure 4: The variation of the bending and compressive strength of graphene oxide reinforced cement based composite material with the changes of the mixing amount and water-cement ratio of graphene oxide.

Fig. 4(a) described the variation rules of the mechanical properties of graphene oxide reinforced cement based composite material with the variation of the mixing amount of graphene oxide when the water-cement ratio was 0.35 . As shown in the figure, the influence of the mixing amount of graphene oxide on the compressive and bending strength of the test specimens was consistent, i.e. increase firstly and then decrease; the compressive and bending strength was maximum when the mixing amount of graphene oxide was $0.03 \%$, and there was a growth rate of $23.83 \%$ and $10.85 \%$, indicating that the improvement of the bending strength was more obvious when the mixing amount of graphene oxide was within a certain range; when the mixing amount exceeded $0.03 \%$, the bending and compressive strength had significant decline and even became lower than that of the blank samples. The first reason might be water demand significantly improved after the addition of cementbased materials because of the extremely large surface energy and specific surface area of graphene oxide. Zhu [21] found that the slump of cement paste which contained $0.05 \%$ graphene oxide reduced by $41.7 \%$, which revealed that water demand sharply increased with the increase of the content of graphene oxide. The second reason might be graphene oxide was prone to gather because of van der Waals attraction when the content of graphene oxide was high. Moreover, many water molecules around were absorbed, leading to inconsistent water-cement ratio and uneven hydrate formation.

Fig. 4(b) shows the variation rules of the mechanical properties of compound cement mortar under different water cement ratio. The mechanical performance of the test specimens which were mixed with graphene oxide was superior to that of the specimens which were not mixed with graphene oxide, and the larger the water-cement ratio, the lower the strength of the 
test specimens. But when the water-cement ratio increased from 0.45 to 0.5 , the strength of the test specimens which were not mixed with graphene oxide significantly declined, and the bending and compressive strength changed more gently. When the water-cement ratio was 0.5 , the growth rates of the bending and compressive strength of the test specimens which were not mixed with graphene oxide were maximum, $73.09 \%$ and $72.35 \%$ respectively. On one hand, residual water evaporated during setting and hardening of cement paste, leading to the generation of large pores; on the other hand, graphene oxide was prone to fill in the micro-pores of the cement paste to improve the structure under a high water cement ratio. But graphene oxide as a nanometer material cannot fill in the large pores left after evaporation of water; therefore, the overall decrease tendency of the strength did not change with the variation of the water cement ratio.

\section{Effects of graphene oxide on the microstructure of graphene oxide reinforced cement-based composite material}

Fig. 5 exhibits the SEM images of the test specimens under different mixing amount of graphene oxide $(0,0.01 \%, 0.03 \%$ and $0.05 \%$ ). The calcium silicate hydrate $(\mathrm{CSH})$ gel and calcium hydroxide $(\mathrm{CH})$ grew in the test specimens which were not mixed with graphene oxide. There were many pores in the hardened cement paste, and the insufficient ettringite inside the pores led to loose connection. But a large amount of ettringite scattering on the surface failed to play the roles of filling and connection, which was not beneficial to the structure of cement mortar. With the addition of graphene oxide, tiny CSH gels in a size of $1 \mu \mathrm{m}$ distributed on the surface of cement particles like a roll leaf (Fig. 5(b)). When the content of graphene oxide was $0.03 \%$, the structure of the hardened cement paste was significantly improved, no isolated hydration products were observed, and CSH structure in the shape of roll leaf which became more even and compact covered on the surface of other crystals and cement particles (Fig. 5(c)). When the content of graphene oxide was $0.05 \%$, a compact and even structure which was composed of various hydrates was observed, but large pores and cracks appeared in the surrounding and flocculent CSH gel scattered on the surface (Fig. 5(d)).

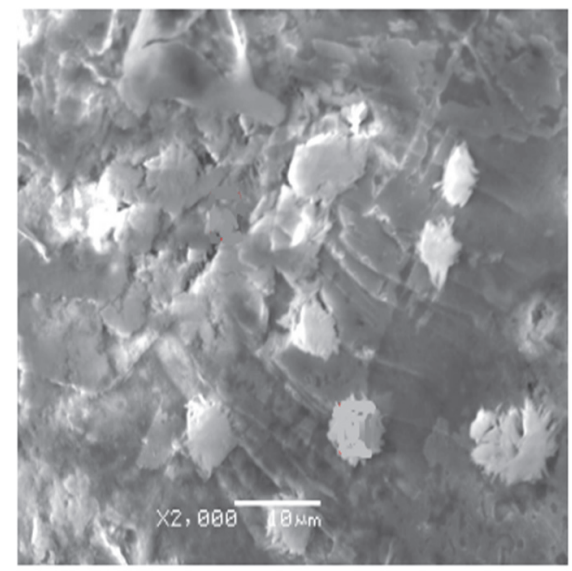

(a) The content of graphene oxide was 0 .

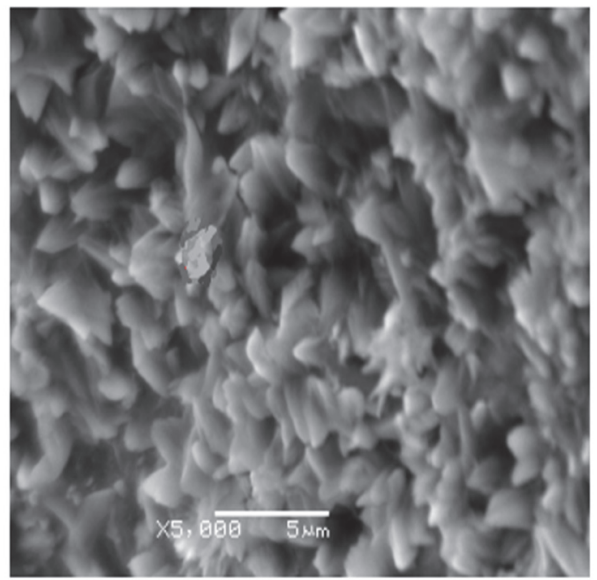

(c) The content of graphene oxide was $0.03 \%$.

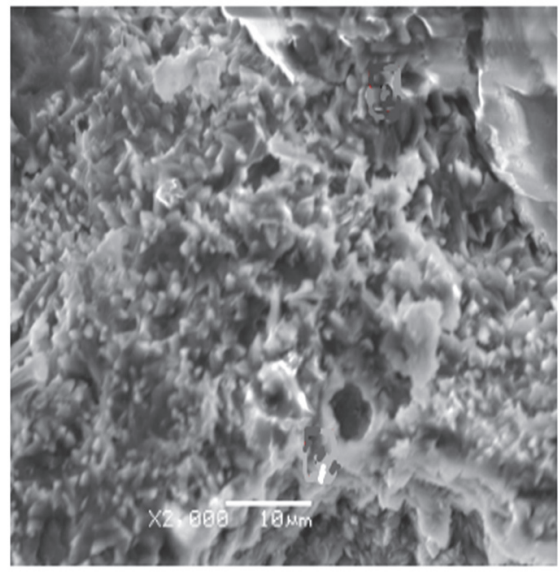

(b) The content of graphene oxide was $0.01 \%$

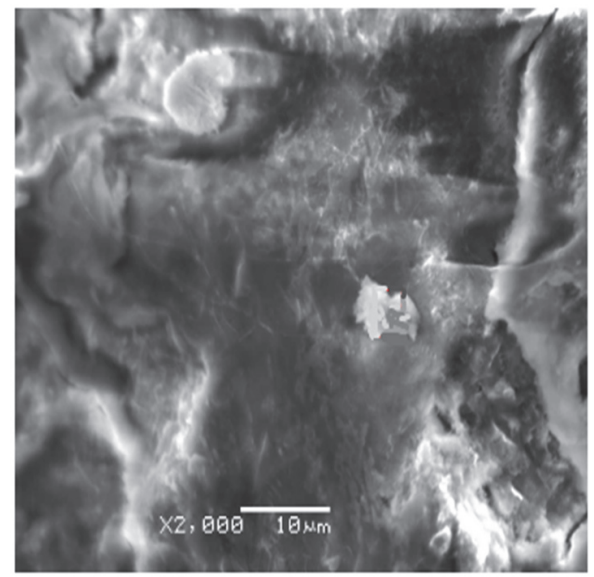

(d) The content of graphene oxide was $0.05 \%$.

Figure 5: The test specimens under different mixing amount of graphene oxide under scanning electron microscope. 


\section{CONCLUSIONS}

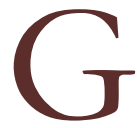

raphene oxide solution was prepared using the improved Hummers method and mixed with cement mortar to

form cement-based composite material to investigate the effects of different mix proportion on the mechanical properties and microstructure of graphene oxide reinforced cement based composite material. The following conclusions were obtained.

(1) When the water cement ratio was fixed. The mechanical strength of cement mortar increased with the increase of the content of graphene oxide and reached the maximum when the content of graphene oxide was $0.03 \%$; the increase of the bending strength $(23.83 \%)$ was the most obvious. Those findings suggested the addition of graphene oxide could greatly improve the toughness of cement.

(2) When the content of graphene oxide was $0.03 \%$, cement mortar was the same with the traditional cement; the larger the water cement ratio, the lower the strength. But the specimens which were added with graphene oxide effectively slowed the decline of the strength of the specimens with high water cement ratio $(\mathrm{W} / \mathrm{C}=0.5)$. Compared to the blank specimens, the bending and compressive strength of the specimens which was mixed with graphene oxide had an improvement of $73.09 \%$ and $72.35 \%$.

(3) The analysis of the microstructure suggested that the addition of graphene oxide could affect the growth form and number distribution of cement hydration products. The filling effect, hydration effect and nucleation effect of graphene oxide was notable when the content of graphene oxide was within a certain range. Graphene oxide became the zone for various hydration reactions because of its large specific surface area, which provided a better growth space for hydration products. It could reduce the porosity of the hardened cement paste and make the structure of cement mortar tighter; leading to the improved strength and ductibility.

The above research results which were similar to the research results of $\mathrm{Xu}$ et al. [22] were meaningful to improve the bending strength and crack resistance of cement-based materials and extend their service life, which can provide a reference for the future studies.

\section{ACKNOWLEDGMENTS}

his study was supported by the Key Laboratory of Architectural Structure (project no. CP12015005).

\section{REFERENCES}

[1] Boulekbache, B., Hamrat, M. and Chemrouk, M., et al., (2012). Influence of yield stress and compressive strength on direct shear behaviour of steel fibre-reinforced concrete, Construction and Building Materials, 27(1), pp. 6-14.

[2] Wille, K., Naaman, A.E. and Parra-Montesinos, G.J. (2012). Ultra-high performance concrete and fiber reinforced concrete: achieving strength and ductility without heat curing, Materials and Constructure, 3, pp. 1-16.

[3] Han, Y. (2015). Study on properties of cement based composites based on grapheme, Low Temperature Architecture Technology, 2, pp. 4-6.

[4] Nobili, A., Lanzoni, L. and Tarantino, A.M. (2013). Experimental investigation and monitoring of a polypropylenebased fiber reinforced concrete road pavement, Construction and Building Materials, 47, pp. 888-895.

[5] Liu, X.H., Duan, Y., Zhou, W., et al. (2013). Modeling the piped water cooling of a concrete dam using the heat-fluid coupling method, Journal of Engineering Mechanics, 139(9), pp. 1278-1289.

[6] Freyne, S., Ramseyer, C. and Giebler, J. (2012). High-performance concrete designed to enhance durability of bridge decks: oklahoma experience, Journal of Materials in Civil Engineering, 24(7), pp. 933-936.

[7] Yu, H.Y., Zhao, R.X. and Zou, H.F. (2005). Development and Prospect of Cement-based Composite Materials. Henan Building Materials, 3, pp. 21-19.

[8] Feng, N.Q. (2003). Development and Application of High Performance Concrete, Construction Technology, 32(4), pp. $1-6$.

[9] Cao, M.L. (2015). Effect of graphene on mechanical properties and microstructure of cement paste, Journal of Harbin Institute of Technology, 47, pp. 26-30. 
[10] Li, G.Y. and Wang, P.M. (2005). Microstructure and mechanical properties of carbon nanotubes cement matrix composites, Journal of The Chinese Ceramic Society, 33(1), pp. 105-108.

[11] Lao, Y.S., Zhang, L., Wang, X.P., et al. (2014). Research progress in effect of nanoparticles on the performance of cement-based materials, Materials Review, 28(3), pp. 93-96.

[12] Yang, Q.H. (2011). Dreams may come: from fullerene, Carbon nanotube to grapheme, New Carbon Material, 26(1), pp. 1-4.

[13] Du, H.J., Pang, S.D. (2015). Transport of water and chloride ion in cement composites modified with graphene nanoplatelet, Key Engineering Materials, 629-630(1), pp. 162-167.

[14] Yang, Y.G., Chen, C.M., Wen, Y.F., et al. (2008). Oxidized graphene and graphene based polymer composites, New Carbon Materials, 23(3), pp. 193-200.

[15] Babak, F., Abolfazl, H., Alimorad, R., et al. (2014). Preparation and Mechanical Properties of Graphene Oxide: Cement Nanocomposites, The Scientific World Journal, 1, pp. 1-10.

[16] Liang, J.J., Huang, Y., Zhang, L., et al, (2009). Molecular-Level Dispersion of Graphene into Poly(vinyl alcohol) and Effective Reinforcement of their Nanocomposites, Advanced Functional Materials, 19, pp. 2297-2302.

[17] Morsy, M.S., Alsayed, S.H. and Aqel, M. (2011). Hybrid effect of carbon nanotube and nano-clay on phsico-mechanical properties of cement mortar, Construction \& Building Materials, 25, pp. 145-149.

[18] Cwirzen, A., Habermehl-Cwirenzen, K. and Penttala, V. (2008). Surface decoration of carbon nanotubes and mechanical properties of cement/carbon nanotubes composites, Advances in cement research, 20(2), pp. 65-73.

[19] Makar, J.M., Margeson, J.C. and Luh, J. (2005). Carbon nanotube/cement composites-early results and potential applications, NRC Publications Record, pp. 1-10.

[20] Yu, S., Dong, Z., et al. (2015). Effect of grapheme oxide on the rheological properties of cement pastes, Construction \& Building Materials, 96, pp. 20-28.

[21] Zhu, P., Li, H., et al. (2015). Mechanical properties and microstructure of a grapheme oxide-cement composite, Cement \& Concrete Composites, 58, pp. 140-147.

[22] Xu, Y.D., Zeng, J.Q., Chen, W., et al. (2018). A holistic review of cement composites reinforced with graphene oxide, Construction \& Building Materials, 171, pp. 291-302. 